\title{
An analysis of temperature distribution in solar photovoltaic module under various environmental conditions
}

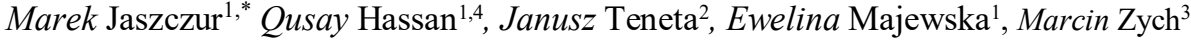 \\ ${ }^{1}$ AGH University of Science and Technology, Faculty of Energy and Fuels, Poland \\ ${ }^{2}$ AGH University of Science and Technology, Faculty of Electrical Engineering, Automatics, Poland \\ ${ }^{3}$ AGH University of Science and Technology, Faculty of Geology, Geophysics and Environmental Protection, Poland \\ ${ }^{4}$ University of Diyala, Department of Mechanical engineering, Diayal, Iraq
}

\begin{abstract}
The operating temperature of the photovoltaic module is an important issue because it is directly linked with system efficiency. The objective of this work is to evaluate temperature distribution in the photovoltaic module under different environmental conditions. The results shown that photovoltaic module operating temperature depends not only on the ambient temperature or solar radiation dependent but also depends on wind speed and wind direction. It is presented that the mounting conditions which are not taken into consideration by most of the literature models also play a significant role in heat transfer. Depends on mounting type an increase in module operating temperature in the range $10-15^{\circ} \mathrm{C}$ was observed which cause further PV system efficiency decrease of about 3.8-6.5\%.
\end{abstract}

\section{Introduction}

Due to the international regulations regarding global warming and increasing $\mathrm{CO}_{2}$ emissions, the electrical energy production has to take into account the environmental aspect. The care for the environment is required because the Earth pollutions significantly influence the quality and the length of life for all living organisms. The additional problem is that fossil fuels are non-renewable and one day will be depleted. On the other hand, rapid growth in renewable energy systems has reached in 2016 the faster growing with global investments than traditional systems [1]. One of the widely used renewable energy systems which provide the direct method of converting solar energy into electrical energy is the photovoltaic system. Despite the significant progress that has been already made, the increase in electrical efficiency and the reduction of the production cost are to be still important goals. The performance of the photovoltaic system depends on a large number of factors such as module specifications, mounting scheme, module inclination, solar radiation, wind speed, ambient temperature, pollution or shadowing. The energy conversion efficiency in the photovoltaic module has high depends on the module temperature. The weak cooling mounting, high ambient temperature and high solar irradiation have a negative influence on the module energy conversion efficiency [2]. In the critical situation of inverter overheat the system will radically decrease the generating power or even shut down the system. The photovoltaic cell efficiency designed under Standard Test Conditions STC and varied depending on the cell type (polycrystalline silicon 16.0-17\%, monocrystalline silicon up to $20 \%$ and thin film amorphous silicon about
7.5\%) [3] and the cell operating temperature. With increasing the photovoltaic temperature, the current increase but the voltage decreases and final effective electrical power decrease [4]. The module efficiency is usually defined at the Standard Test Conditions STC (temperature $25{ }^{\circ} \mathrm{C}$, solar radiation $1000 \mathrm{~W} / \mathrm{m}^{2}$, wind speed $1 \mathrm{~m} / \mathrm{s}$ ).

There are several studies investigated the influence of temperature and thermal effect on photovoltaic energy and efficiency. The review concentrating on model validation, i.e. on temperature from measured and available models has been prepared by Santiago et al. [5]. The study analysed twenty models for predicting module operating temperature with different complexity. Perović et al. [6] have presented a model for estimation PV module temperature used energy balance equation. Authors validated the model with experiments and compared with two other models using different methodology. The results illustrated good agreement with the experiments measured data. Estimation for the heat transfer coefficient for photovoltaic module based on the empirical or theoretical relationship has been prepared by Kendoush [7]. The study was conducted using theoretical analysis for the fluid flowing across the flat plate in order to determine mass and heat flow. Zondag et al. [8] analysed the thermal performance of hybrid collectors with a-Si photovoltaic cells. The results showed that the annual degradation in the electrical efficiency is $7.6 \%$ due to temperature effect. By using experimental measurements, Hassan et al. [9] analysed the temperature effect on the performance of the photovoltaic system and energy production. The results of the analysis confirmed that the operating temperature of a module plays a vital

\footnotetext{
* Corresponding author: jaszczur@agh.edu.pl
} 
role in the conversion process and the electrical efficiency and power output are significantly influenced. Ceylan et al. [10], analysed an effect of ambient temperature on the photovoltaic module temperature. Their results developed linear and nonlinear models for predicting module temperature effect on the output power and efficiency drop. They concluded that the non-linear model is more efficient than linear. Comprehensive analysis of PV modules by in-situ experimental measurement performed with 3-D numerical simulation in order to model heat transfer from PV module have been by Jaszczur et al. [11]. The results allow developing a new model for PV panel evaluation which includes all vital environmental factors (ambient temperature, incident solar, wind speed) as well as geometrical conditions or mounting conditions (using Ross coefficient). Hassan et al. [12] used energy balance equations and NOCT to prepare the new model for predicting PV module temperature. Their results showed that by using this model the yearly energy losses due to temperature, effects could be about $23 \%$ for $1 \mathrm{~kW}$ PV system. An accurate determination of the PV module operating temperature is an important issue. Koehl et al. [13] validate two models for prediction module temperature in different climatic regions and getting accurate results for PV module temperature evaluation. In this research, an analysis of temperature distribution in the photovoltaic module under various environmental conditions was performed. The real system analysis was base on locally measured weather conditions and verify using in-situ experimental measurement and CFD computer modelling.

\section{Experimental and numerical set-up}

The experimental set-up consists of two BrukBet BEP260W polycrystalline photovoltaic modules (temperature coefficient of power $-0.40 \% /{ }^{\circ} \mathrm{C}$ and $1.62 \mathrm{~m}^{2}$ of surface area, white back sheet) grid-connected, and two BrukBet BEP260W like modules without PV cells (first with white and second with a black back sheet) presented in Fig. 1(a). An analysed modules were adjusted at tilt angle $\beta=35^{\circ}$ and azimuth $\gamma=20^{\circ}$ West and located at the roof of $\mathrm{C} 3$ building, AGH University of Science and Technology in the city centre of Kraków, Poland (50.066354N, 19.918191E).

The acquisition system for temperature and solar radiation include 4 Advantech ADAM4018 DAQ modules that provide programmable input ranges on all channels, computer unit with data acquisition software and storage. As temperature sensors, eight T-type thermocouples were used (four thermocouples per PV modules) located in the recommended by standard point see Fig.1(b). The signals from thermocouples were acquired every second, and the average value was recorded every 60 seconds.

The ambient temperature, wind speed and solar irradiation were obtained from the local weather station. The signals from weather station sensors were acquired every second, and the average value was recorded for analysis every 5 minutes.
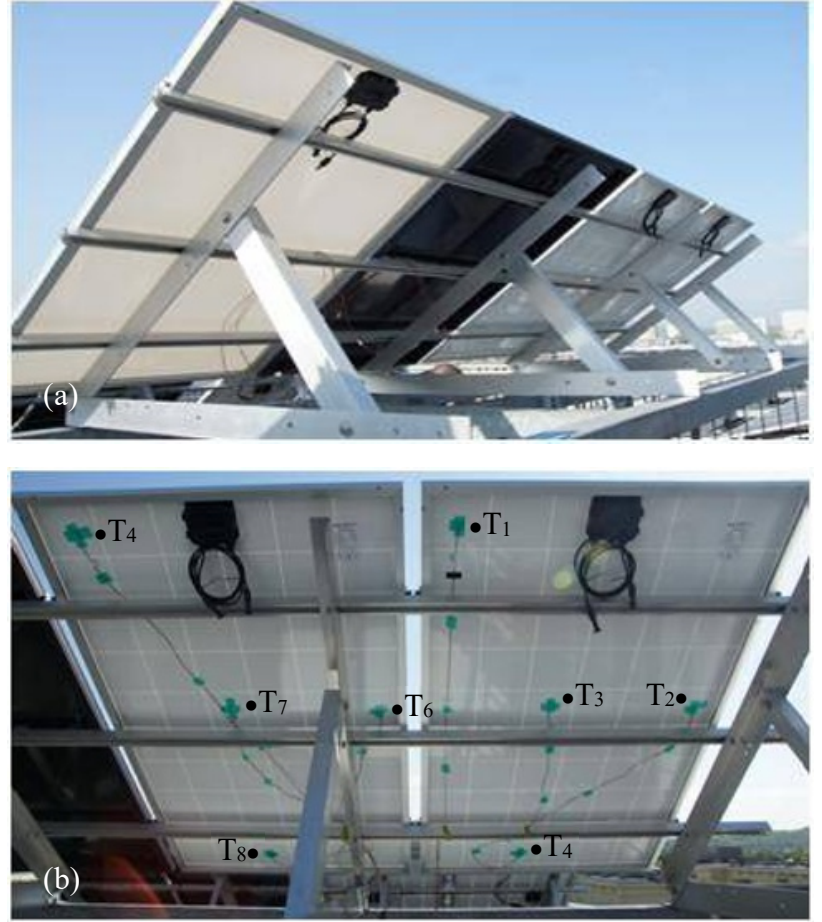

Fig.1. An experimental set-up with the mounting system (a) and thermocouples arrangement (b).

3-D model of the photovoltaic module with the mounting system has been created in order to analyse fluid flow and temperature distribution. As a numerical solver Fluent v.18 was used. The geometry under consideration and key heat transfer components are shown in Fig. 2. The module size is $1.654 \times 0.989 \times 0.04 \mathrm{~m}$ and glass thickness is $5 \mathrm{~mm}$. Instead of the multilayer system, it is assumed the modules one layer with an averaged thermal properties. Computational domain size was $4.2 \times 2.8 \times 2.2 \mathrm{~m}$, and has been filled with hex-dominant mesh elements, while in order to solve for boundary layer prismatic elements were adjusted. Additionally for the region with the high turbulence intensity finer mesh has been used. Based on the preliminary test analysis mesh with about 500,000 elements has been found to give a mesh-independent solution.

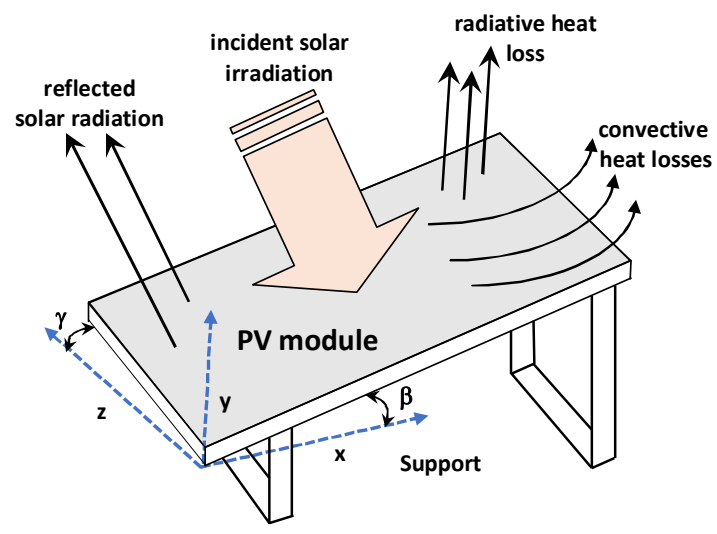

Fig.2. The geometry and the key heat transfer components.

It assumed that that fluid is Newtonian with constant fluid and solid properties presented in Table 1. 
Table 1. Fluid and solid properties.

\begin{tabular}{|c|c|c|c|c|}
\hline $\begin{array}{c}\text { Material } \\
\text { name }\end{array}$ & $\begin{array}{c}\text { Specific } \\
\text { heat } \\
\mathbf{J} / \mathbf{k g K}\end{array}$ & $\begin{array}{c}\text { Density } \\
\mathbf{k g} / \mathbf{m}^{\mathbf{3}}\end{array}$ & $\begin{array}{c}\text { Viscosity/ } \\
\text { Emissivity } \\
\mathbf{k g} / \mathbf{m s} / \mathbf{-}\end{array}$ & $\begin{array}{c}\text { Thermal } \\
\text { conductivity } \\
\mathbf{W} / \mathbf{m K}\end{array}$ \\
\hline Air & 1006.43 & 1.225 & $1.78 \cdot 10^{-5}$ & 0.0242 \\
\hline Panel & 700 & 2700 & 0.92 & 197 \\
\hline Soil & 1600 & 1600 & 0.95 & 2 \\
\hline
\end{tabular}

The considerations for the mathematical model eq. (1)-(3) are: steady state negligible viscosity dissipation and the use of the Boussinesq approximation. The time-averaged equations for continuity, momentum and energy can be written as follows:

$$
\begin{gathered}
\frac{\partial \bar{U}_{i}}{\partial x_{i}}=0 \\
\bar{U}_{j} \frac{\partial \bar{U}_{i}}{\partial x_{j}}=-\frac{1}{\rho} \frac{\partial \bar{P}}{\partial x_{i}}+v \frac{\partial^{2} \bar{U}_{i}}{\partial x_{j}^{2}}-\frac{\partial}{\partial x_{j}}\left(\overline{u_{i} u_{j}}\right), \\
\bar{U}_{j} \frac{\partial \bar{T}}{\partial x_{j}}=\kappa \frac{\partial^{2} \bar{T}}{\partial x_{j}^{2}}-\frac{\partial}{\partial x_{j}}\left(\overline{u_{j} \theta}\right),
\end{gathered}
$$

where $x_{i}, x_{j}$ are the Cartesian coordinates of the system, $\bar{U}, \bar{P}, \bar{T}$ are the mean velocity, dynamic pressure and temperature; $v, \kappa$ are fluid viscosity and thermal diffusivity. Turbulent a semi-empirical 2-equation eddy viscosity realizable $\mathrm{k}-\varepsilon$ model was used. This model is based on the Boussinesq hypothesis, and Reynolds stresses are expressed regarding mean velocity gradients and that the turbulent eddy viscosity is related to the turbulent kinetic energy and the dissipation rate of turbulent kinetic energy as follows:

$$
\begin{gathered}
-\rho \overline{u_{i} u_{j}}=\tau_{i j}=\mu_{T}\left(\frac{\partial \bar{U}_{i}}{\partial x_{j}}+\frac{\partial \bar{U}_{j}}{\partial x_{i}}\right)=2 \mu_{T} \cdot S_{i j}, \\
\mu_{T}=\rho \cdot C_{\mu} \frac{k^{2}}{\varepsilon} ; \overline{u_{i} \theta}=-\left(\kappa+\frac{v_{T}}{\operatorname{Pr}_{T}}\right) \frac{\partial \bar{T}}{\partial x_{i}} .
\end{gathered}
$$

Turbulence model Realizable $k-\varepsilon$ posses an improved formulation for the turbulent viscosity. The equation for the turbulent kinetic energy and the dissipation rate are as follows:

$$
\begin{gathered}
\frac{\partial}{\partial x_{i}}\left(\bar{U}_{i} \cdot k\right)=\frac{\partial}{\partial x_{i}}\left(\frac{v_{e f f}}{\sigma_{k}} \frac{\partial k}{\partial x_{i}}\right)+P_{k}-\varepsilon, \\
\frac{\partial}{\partial x_{i}}\left(\overline{U_{i}} \cdot \varepsilon\right)=\frac{\partial}{\partial x_{i}}\left(\frac{v_{e f f}}{\sigma_{\varepsilon}} \frac{\partial \varepsilon}{\partial x_{i}}\right)+C_{1} \cdot S \cdot \varepsilon-\frac{C_{2} \cdot \varepsilon^{2}}{k+\sqrt{v \cdot \varepsilon}},
\end{gathered}
$$

where $k$ and $\varepsilon$ are turbulence kinetic energy and dissipation rate, $P_{k}$ is the turbulent kinetic energy production $\mu_{\text {eff }}=\mu+\mu_{T}$ and $v_{\text {eff }}=\mu_{\text {eff }} / \rho$ are turbulent effective viscosity. The model constants are:

$$
C_{l}=\max \left[0.43, \frac{\eta}{\eta+5}\right] ; \eta=S_{\varepsilon}^{k} ; C_{e l}=1.44 ; \sigma_{k}=1.0 ; \sigma_{\varepsilon}=1.2
$$

$$
\begin{gathered}
S=\sqrt{2 S_{i j} S_{i j}} ; \quad C_{\mu}=\frac{1}{A_{0}+A_{S} \frac{k \sqrt{s_{i j} s_{i j}+\widetilde{\Omega}_{i j} \widetilde{\Omega}_{i j}}}{\varepsilon}} ; \\
S_{i j}=\frac{1}{2}\left(\frac{\partial \bar{U}_{j}}{\partial x_{i}}+\frac{\partial \bar{U}_{i}}{\partial x_{j}}\right) ; \widetilde{\Omega}_{i j}=\Omega_{\mathrm{ij}}-2 \varepsilon_{\mathrm{ijk}} \omega_{\mathrm{k}} ; \\
\Omega_{i j}=\bar{\Omega}_{\mathrm{ij}}-2 \varepsilon_{\mathrm{ijk}} \omega_{\mathrm{k}} ; \mathrm{A}_{0}=4.04 ; \mathrm{A}_{\mathrm{S}}=\sqrt{6} \cos \phi ; \\
\phi=\frac{1}{3} \cos ^{-1}(\sqrt{6} W) ; W=\frac{S_{i j} S_{j k} S_{k i}}{\tilde{S}^{3}} .
\end{gathered}
$$

The heat transfer model includes solar model and radiation heat transfer, model. For the radiative heat transfer Surface-to-Surface (S2S) radiation model is used:

$$
\begin{aligned}
q_{o u t, k} & =\varepsilon_{k} \sigma T_{k}^{4}+\rho_{k} q_{i n, k}, \\
A_{k} q_{i n, k} & =\sum_{j=1}^{N} A_{j} q_{o u t, k} F_{j k},
\end{aligned}
$$

where $q_{o u t, k}$ and $q_{\text {in,k }}$ are energy flux leaving the surface and energy flux incident on the surface from surroundings; $A_{k}$ is an area of $k$-surface, $F_{j k}$ is view factor between $k$-surface and $j$-surface. Average air velocity and turbulence intensity profiles for roughness length $0.03 \mathrm{~m}$ are employed as an inlet boundary conditions. At the domain exit, a uniform zero gauge pressure boundary condition is used. At the side walls pressure outlet boundary condition were applied. The bottom wall has been treated as a rough wall with no-slip boundary condition. At the inlet of the domain the air temperature $T_{a}$ equal to the values obtained from measurements have been applied. Solar radiation is applied to the thermal radiation model as an incident solar radiation in the range $100-1000 \mathrm{~W} / \mathrm{m}^{2}$ depend on the case.

\section{Results and discussion}

The incident global and diffuse solar radiation at horizontal surface $\beta=0^{\circ}$ and tilted at $\beta=35^{\circ}$ (azimuth $\gamma=20^{\circ}$ ) and wind speed and ambient temperature are shown in Fig. 3 for selected sunny day 07.06.2018.

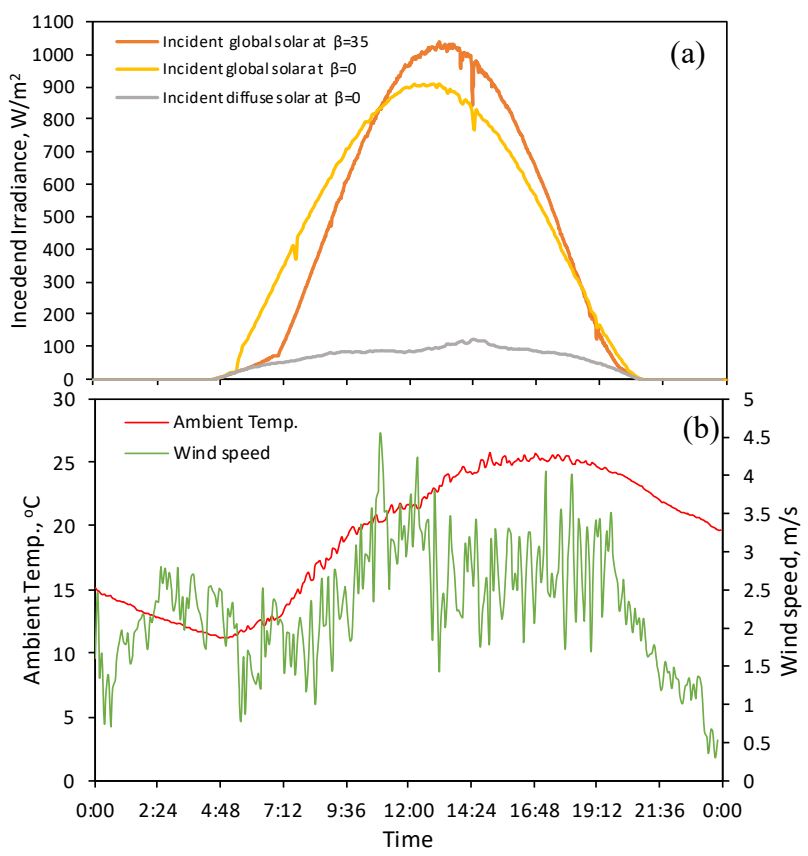

Fig. 3. The solar irradiation (a), wind speed and ambient temperature (b). 
One may infer from results that the incident solar radiation, at $\beta=35^{\circ}$ has lower magnitude and the signal is a delay in the morning hours due to pyranometer azimuth and inclination.

Figure 4(a) shows the temperature of polycrystalline panels with tilted angle $\beta=35^{\circ}$ for selected sunny day 07.06.2018. The maximum temperatures recorded during the day is $50.9^{\circ} \mathrm{C}$. It can be seen that at different points of the panel (T1-T4) temperature during high solar irradiation may vary significantly as a result of different heat transfer from various part of the photovoltaic module (top, side or corners). In Figure 4(b)-(c) temperature from the modules with black and white back sheet (and without silicon cells) are presented for $\beta=35^{\circ}$. Much higher temperature raising up to equal to $57.5^{\circ} \mathrm{C}$ is observed for a panel with a black back sheet while for the panel with a white back sheet the maximum temperature $34.4^{\circ} \mathrm{C}$ was recorded during the day.

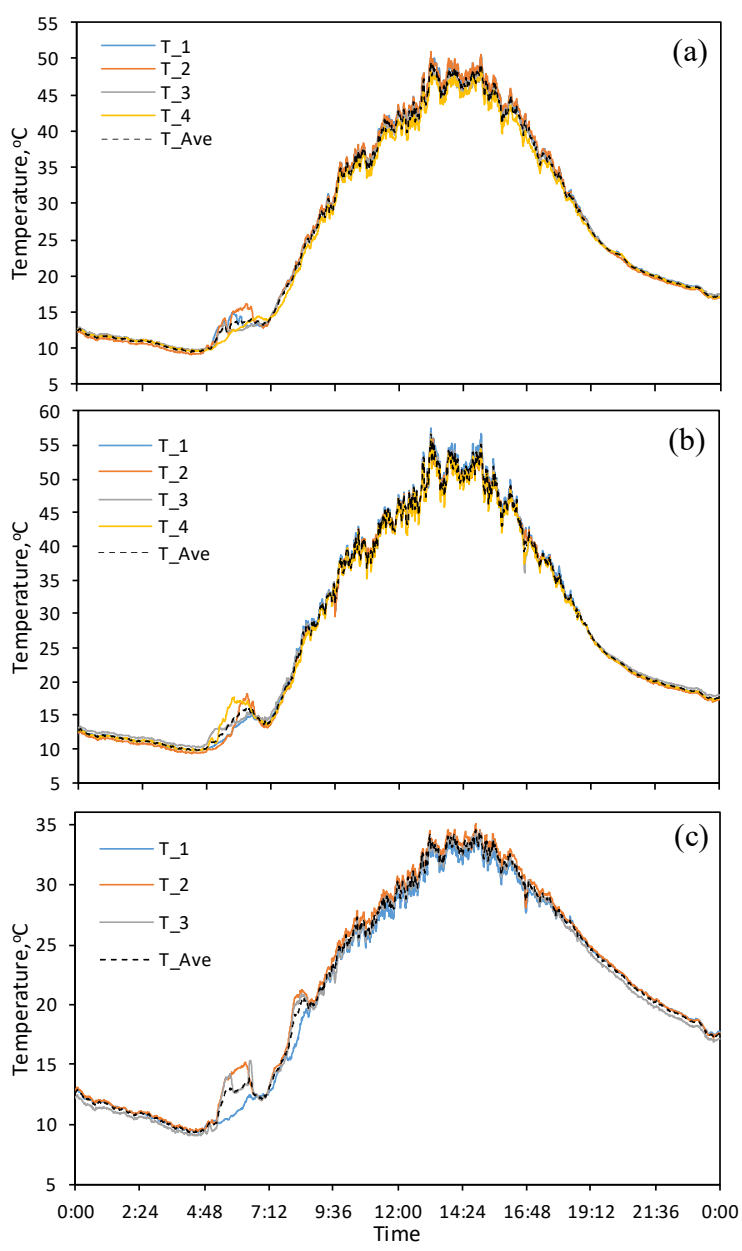

Fig. 4. Module temperature: with Si-cells (a), black back sheet (b), white back sheet (c) and for $\beta=35^{\circ}$.

In order to evaluate temperature distribution at module surface, Computational Fluid Dynamics (CFD) analysis was performed for the panels with titled angles $\beta=0,15^{\circ}$ and $35^{\circ}$ and environmental conditions, solar radiation $G_{T}$ $=470 \mathrm{~W} / \mathrm{m}^{2}$, wind speed $V_{w}=3.1 \mathrm{~m} / \mathrm{s}$ and ambient temperature $T_{a}=8{ }^{\circ} \mathrm{C}$. In Figure 5(a)-4(d) the flow field around the module is shown. Except the configuration presented in Figure 5(b) wind direction is opposite to the
$\mathrm{X}$-axis direction $\left(V_{w}=-3.1 \mathrm{~m} / \mathrm{s}\right)$ while in Figure $5(\mathrm{~b})$ air flow has the same magnitude but the flow is from the module left side. In Figure 5(d) module tilt angle is $\beta=$ $0^{\circ}$, and the space under the module is closed which significantly reduces heat transfer from the bottom surface.

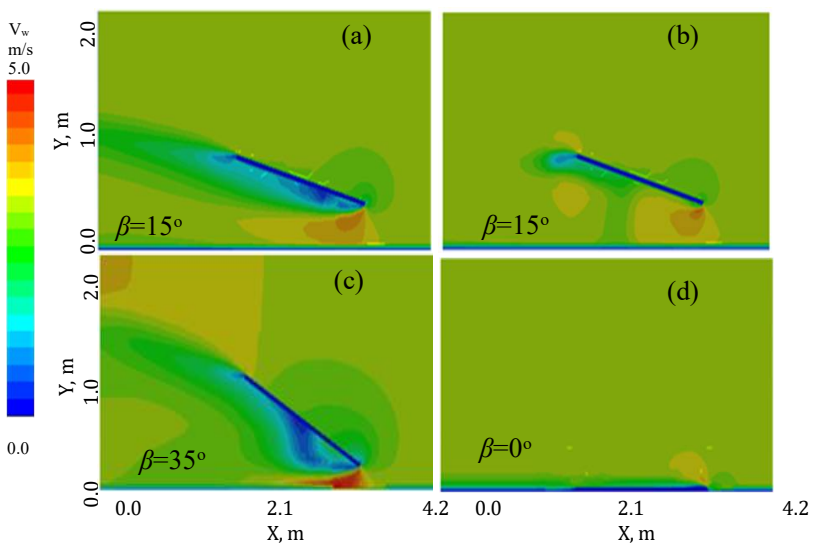

Fig.5. Velocity field around module for different tilt angle: $\beta=15^{\circ}(\mathrm{a}), \beta=15^{\circ}(\mathrm{b}), \beta=35^{\circ}$ (c), $\beta=0^{\circ}$ (d) and air flow direction

The temperature field for the same conditions as presented in Figures 5 are presented in Figures 6. One can see from this figures that temperature distribution for similar weather parameters differs significantly. The highest temperature has been obtained for module with tilt angle $\beta=0^{\circ}$ when the cooling conditions are the worst cooling while the lowest temperature of the PV module is seen for the tilt angle equal to $15^{\circ}$ when the of air flow is from the module (left) side - see Fig. 6(b).

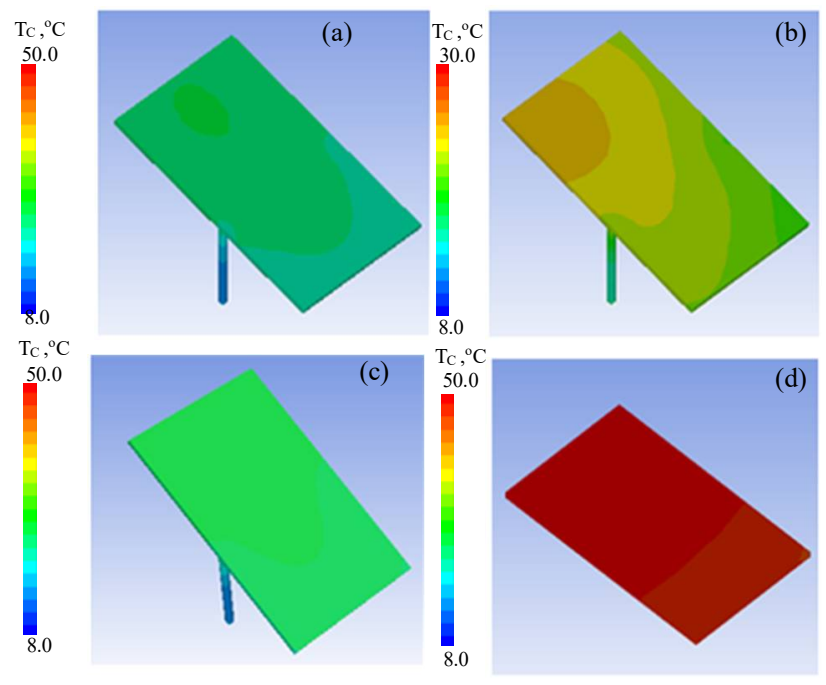

Fig. 6. Temperature at the module surface for different tilt angle: $\beta=15^{\circ}$ (a), $\beta=15^{\circ}$ (b), $\beta=35^{\circ}$ (c), $\beta=0^{\circ}$ (d) and air flow direction.

The essential parameters which have considerable influence on the module operating temperature are the solar irradiation, ambient temperature $T_{a}$ and wind speed $V_{w}$ The impact of above parameters on the mean module operating temperature are shown in Figures 7 together with experimental measurement. It can be seen that for low airspeed the module temperature becomes very high which effect PV module performance. 

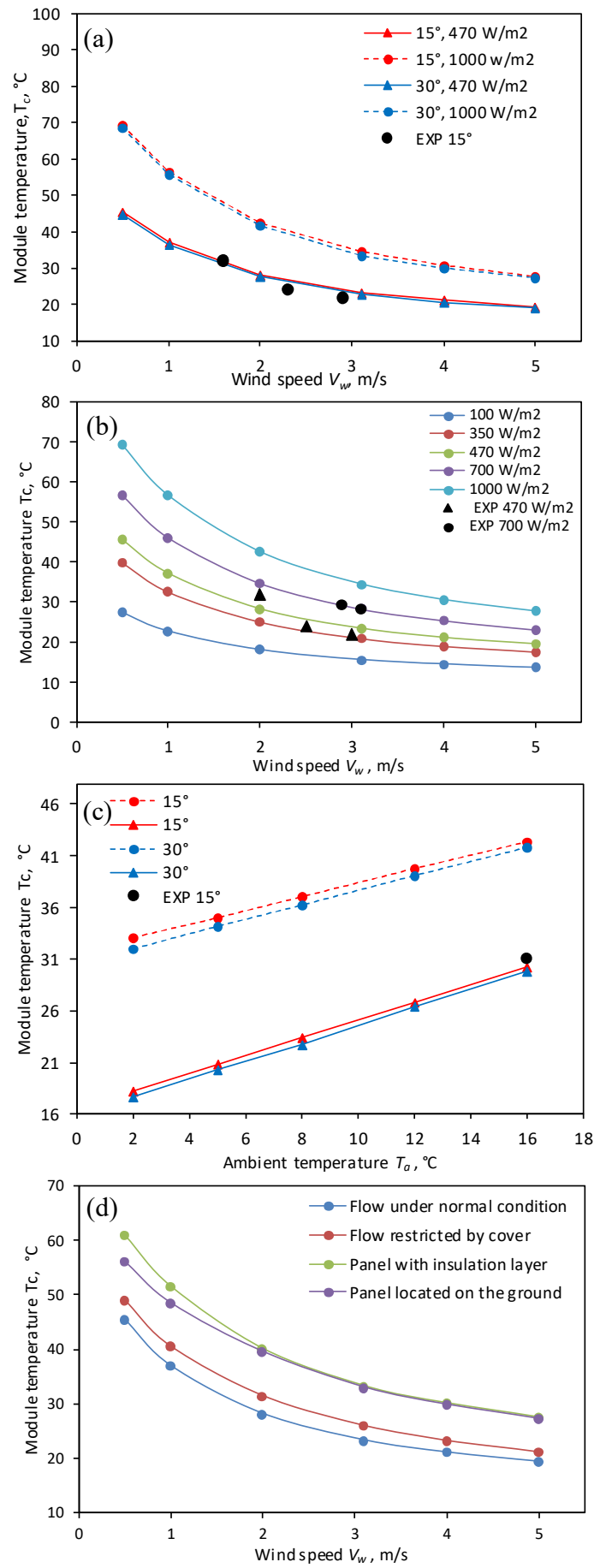

Fig. 7. The average module temperature $T_{c}$ vs.: wind speed $V_{w}$ (a-b), ambient temperature $T_{a}$, (c) mounting configuration (d).

One of the important parameters is related to the module mounting conditions. Typically module top surface is well cooled. However, the bottom module surface heat transfer can differ depending on mounting configuration significant. For the conditions which allow for air flow from two sides the module temperature become the lowest. When the flow below module is restricted the temperature, an increase about $2-4^{\circ} \mathrm{C}$ is observed. On the other hand when the module is mounted horizontally, or the module bottom surface is insulated (wall integrated configuration) poor heat transfer causes additional module temperature increase about $10.0^{\circ} \mathrm{C}$.
Using numerical and experimental data correlation for module temperature $T_{c}$ can be created which takes into account all important phenomena parameters: solar irradiation, ambient temperature, wind speed and the mounting conditions. The proposed correlation uses four parameters responsible for all crucial phenomena. In the literature, several relationships have been advised however most of them use two or three parameters only. In the present work modification of the following relationship will be used [14]:

$$
T_{C}=T_{a}+k G_{T} .
$$

In this very popular and straightforward linear expression, no wind effect is taken into account, but the mounting condition does. eq. (10) depends on the one $\mathrm{k}$, which is known as the Ross coefficient [15]. In the literature models which take into account wind speed are proposed however without mounting configuration consideration [16]:

$$
T_{C}=0.943 T_{a}+0.028 G_{T}-1.528 V_{w}+4.3 .
$$

In this work the extended formula of eq.(10) but taking into account air velocity is proposed in the as follows:

$$
T_{C}=T_{a}+k G_{T}+e^{\left(3.75-0.75 V_{w}\right)} .
$$

Proposed correlation takes into account ambient temperature, solar irradiation, wind speed as well as a mounting configuration including PV modules arrangement. The model correlation eq.(12) accuracies have been validated using: root mean squire error (RMSE), the mean bias error (MBE) and the coefficient of determination $\left(\mathrm{R}^{2}\right)$ :

$$
\begin{gathered}
R M S E=\sqrt{\frac{1}{N} \sum_{i=1}^{N}\left(T_{c a l, i}-T_{\text {exp }, i}\right)^{2},} \\
M B E=\frac{1}{N} \sum_{i=1}^{N}\left(T_{c a l, i}-T_{\text {exp }, i}\right), \\
R^{2}=\frac{\sum_{i=1}^{N}\left(T_{\text {cal }, i}-\bar{T}_{\text {exp }}\right)^{2}}{\sum_{i=1}^{N}\left(T_{\text {exp }, i}-\bar{T}_{\text {exp }}\right)^{2}},
\end{gathered}
$$

where $\mathrm{N}$ indicates a number of measurements, while $T_{\text {cal }, i}$ and $T_{\text {exp }, i}$ are obtained from the model equation or measured respectively. Table 2 shows the proposed model's accuracy indicators. As can be seen, all indicators show very good accuracy of the proposed model.

Table 2. The models accuracies statistical indicators.

\begin{tabular}{|c|c|c|c|}
\hline Model & MBE & RMS & $\mathbf{R}^{\mathbf{2}}$ \\
\hline Proposed model eq. (12) & 0.72 & 2.71 & 0.93 \\
\hline
\end{tabular}

\section{Conclusions}

The operating temperature of the PV module panel is an important issue because it is directly linked with photovoltaic system efficiency. In the present work, the temperature distribution in the PV module is analysed using computer modelling and experimental 
measurement. Presented results show large temperature variations, and measured temperature for the white back sheet panel was more than $20^{\circ} \mathrm{C}$ lower than for other configurations which translate into at least an $8 \%$ decrease in module performance.

The analysis shows that module operating temperature depends not only on ambient temperature and solar irradiation what is taken into account by most of the models but also depends on wind speed and wind direction. It has shown that the mounting conditions also play a significant role and may cause an additional module temperature increase of about $10^{\circ} \mathrm{C}$ which to turn into further module efficiency decrease about (3.8-6.5) \% for mono and polycrystalline modules (assuming ($0.38-0.42) \% /{ }^{\circ} \mathrm{C}$ ).

The results enable the development of a model for the photovoltaic module operating temperature. The proposed model is very much sought after by the system designers, computer software and system malfunction detection tools and takes into account all basic phenomena parameters such as solar irradiation, ambient temperature, wind speed and the mounting conditions.

\section{Acknowledgement}

The photovoltaic installation was funded by the National Fund for Environmental Protection and Water Management, Grant 139/2015/Wn06/OA-is-ku/D. This work was partially financed by AGH UST Rector Grant 35/2018 and AGH University Grant No.11.11.210.312. The authors would like to thank MESCO Sp. z o.o. company to provide ANSYS software used in this computer simulation.

\section{References}

1. H. E. Adib, F. Murdock, A. Appavou, B. Brown, A. Epp, A. Leidreiter, C. Lins et al. Renewables 2016 Global Status Report. Global Status Report (2016)

2. R. Anis, M. Abdul-Sadek Nour, Energy Conversion and Management, 36, 1107 (1995)

3. S.A. Kalogirou, R. Agathokleous, G., Energy, 51, 439 (2013)

4. C.W.A. Baltus, J.A. Eikelboom, R.J.C. van Zolingen, R. J. C., 14 $4^{\text {th }}$ European Photovoltaic Solar Energy Conference, Barcelona, 30.06-4.07 (1997)

5. I. Santiago, D. Trillo-Montero, I. M. Moreno-Garcia, V. Pallarés-López, J. J. Luna-Rodríguez, Renewable and Sustainable Energy Reviews, 90, 70 (2018)

6. B. Perović, D. Klimenta, M. Jevtić, M. Milovanović, Zbornik Međunarodne konferencije o obnovljivim izvorima električne energije-MKOIEE, 5, 89 (2017)

7. A. A. Kendoush, International Journal of Thermal Sciences, 48, 188 (2009)

8. H. A. Zondag, D. W. De Vries, W. G. J. van Helden, R. J. C. van Zolingen, A. A. Van Steenhoven, Solar energy ,74, 253 (2003)

9. Q. Hassan, M. Jaszczur, E. Przenzak, E3S Web of Conferences, EDP Sciences, 01028 (2017)
10. I. Ceylan, O. Erkaymaz, E. Gedik, A. E. Gürel, Case Studies in Thermal Engineering, 3, 11 (2017)

11. M. Jaszczur, J. Teneta, K. Styszko, Q. Hassan, P. Burzyńska, E. Marcinek, N. Łopian, Environmental Science and Pollution Research, 1-16. (2018)

12. Q. Hassan, M. Jaszczur, E. Przenzak, J. Abdulateef, Contemporary Problems of Power Engineering and Environmental Protection, 33 (2016)

13. M. Koehl, M. Heck, S. Wiesmeier, J. Wirth, Solar Energy Materials and Solar Cells, 95, 1638 (2011)

14. X. Ju, A. Vossier, Z. Wang, A. Dollet, G. Flamant, Solar Energy, 93, 80 (2013)

15. J. Zhou, Q. Yi, Y. Wang, Z. Ye, Solar Energy, 111, 97 (2015)

16. R. Chenni, M. Makhlouf, T. Kerbache, A. Bouzid, A., Energy, 32, 1724 (2007) 